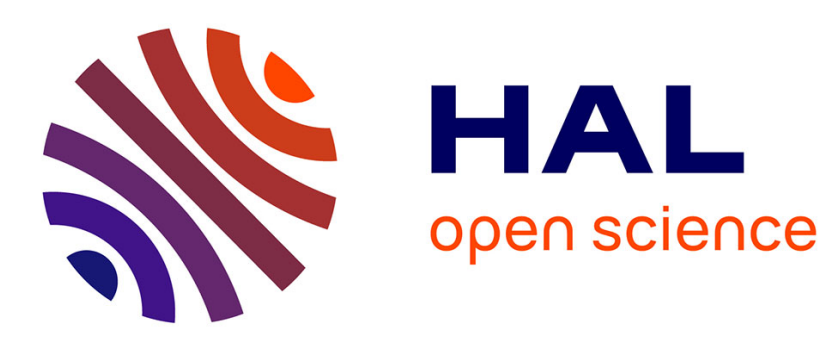

\title{
Barley yellow dwarf disease risk assessment based on Bayesian modelling of aphid population dynamics
}

Frederic Fabre, J.S. Pierre, Charles-Antoine Dedryver, Manuel Plantegenest

\section{To cite this version:}

Frederic Fabre, J.S. Pierre, Charles-Antoine Dedryver, Manuel Plantegenest. Barley yellow dwarf disease risk assessment based on Bayesian modelling of aphid population dynamics. Ecological Modelling, 2006, 193, pp.457-466. 10.1016/j.ecolmodel.2005.08.021 . hal-02656750

\section{HAL Id: hal-02656750 \\ https://hal.inrae.fr/hal-02656750}

Submitted on 29 May 2020

HAL is a multi-disciplinary open access archive for the deposit and dissemination of scientific research documents, whether they are published or not. The documents may come from teaching and research institutions in France or abroad, or from public or private research centers.
L'archive ouverte pluridisciplinaire $\mathbf{H A L}$, est destinée au dépôt et à la diffusion de documents scientifiques de niveau recherche, publiés ou non, émanant des établissements d'enseignement et de recherche français ou étrangers, des laboratoires publics ou privés. 
Version définitive du manuscrit publié dans / Final version of the manuscript published in :

Ecological Modelling, 2006, vol.193, no.3-4, 457-466

\title{
Barley Yellow Dwarf Disease risk assessment based on Bayesian modelling of aphid population dynamics
}

\author{
F. Fabre ${ }^{\mathrm{a}, \mathrm{c}}$, J. S. Pierre ${ }^{\mathrm{b}}$, C. A. Dedryver ${ }^{\mathrm{a}} \&$ M. Plantegenest ${ }^{\mathrm{a}}{ }^{*}$ \\ ${ }^{a}$ UMR INRA/Agrocampus-Rennes, Biologie des organismes et des populations appliquée à la \\ protection des plantes (BiO3P), Domaine de la Motte B.P. 35327, F-35653 Le Rheu cedex, \\ France. \\ b Laboratoire d'Ethologie, Evolution, Ecologie (UMR 6552), Campus de Beaulieu, Avenue \\ du Général Leclerc, 35042 Rennes cedex, France. \\ ${ }^{\mathrm{c}}$ Bayer Crop Science, 16 rue Jean Marie Leclair, 69009 Lyon, France \\ * Corresponding author. Tel.: + 332234855 67; Fax: + 332284851 70; e-mail : \\ Manuel.Plantegenest@agrocampus-rennes.fr
}

\section{Abstract}

Fabre F., Pierre J. S., Dedryver C. A. \& Plantegenest M. 2006. Barley Yellow Dwarf Disease risk assessment based on Bayesian modelling of aphid population dynamics. Ecological Modelling, 193, 457-466.

A stochastic population dynamics model is proposed to improve integrated pest management strategies against the aphid Rhopalosiphum padi, the main Barley Yellow Dwarf Virus (BYDV) vector in winter cereals during autumn in Europe. The model is based on a temperature-dependent simulation of $R$. padi population dynamics. The model requires a single early assessment of the proportion of plants infested by aphids. To account for sampling errors and for uncertainty caused by the numerous factors acting on aphid population dynamics under field conditions, Bayesian statistical inference was used. The model allows assessment of the probability distribution of the area under the curve of the percentage of plants infested by $R$. padi during autumn, a predictor of the need for insecticide sprays against BYDV vectors. The accuracy of model predictions was tested on an independent data set collected from 1995 to 1998 in the main French small grain production areas. The use of this model as a basis for a user friendly decision support system improving BYDV management is discussed.

Keywords: Barley Yellow Dwarf Virus, Decision support system, Integrated pest management, Rhopalosiphum padi, stochastic modelling, temperature. 


\section{Introduction}

Barley yellow dwarf disease (BYD) is one of the most severe cereal diseases in the world (Lister and Ranieri, 1995). It is caused by viruses (Barley yellow dwarf viruses or BYDV and Cereal yellow dwarf viruses or CYDV) transmitted by several aphid species living on Poaceae (Rochow, 1969). On winter barley and winter wheat, yield losses associated with BYD epidemics are mainly caused by autumnal infections (Watson and Mulligan, 1960; Carrigan et al., 1981; Cisar et al., 1982). During this period, Rhopalosiphum padi is the most abundant BYDV vector in Europe (Gillet et al., 1990; Plumb, 1990). The control of BYD on winter cereals mainly relies on insecticides sprays as soon as aphids are established in the crop. However, BYD epidemics are sporadic in time and space and treatments are not required every year in each field. As a consequence, the treated area could be considerably reduced if insecticides were applied only when profitable. This can be achieved by means of a reliable decision making system.

BYD epidemics course in a field strongly depends on the proportion of plants infested by aphids (Irvin \& Tresh, 1990; Kendall et al., 1992; Leclercq-Le Quillec et al., 2000). Fabre et al. (2003) have shown that a decision making system based on the area under the curve of the proportion of plants infested by $R$. padi during autumn (called $I$ thereafter), accurately predicted the profitability of insecticide treatment. However, to be effective, spraying has to be performed at early plant growth stages, before the growth of vector populations in the field (Plumb and Johnstone, 1995). Thus, an early reliable prediction of the value of $I$ should be available.

The temporal dynamics of an aphid population can be derived from its growth rate. The growth rate of $R$. padi depends on both extrinsic and intrinsic factors. The most important intrinsic factor is temperature. Its direct effect has been widely studied (Dean, 1974; Griffiths and Wratten, 1979; Williams, 1980; Elliott and Kieckhefer, 1989). Temperature also indirectly influences the population growth rate of $R$. padi through its effect on natural enemies (Campbell et al., 1974; Wilding, 1970). Several other factors can influence $R$. padi population growth rate: host plant species (Dean, 1973), cereal growth stage (Leather and Dixon, 1981; Kieckhefer and Gellner, 1988), BYDV infection of host plant (Araya and Foster, 1987) and generally host plant health, aphid density (Thirakhupt and Araya, 1992), rain (Araya and Fereres, 1991), aphid morphs (Elliott and Kieckhefer, 1989) and aphid clones (Simon et al., 1991). All together, these factors produce a large variability in the growth rate of aphid populations under field conditions. Some authors have attempted to integrate many of these factors in modelling aphid population dynamics (Carter et al., 1982; Skirvin et al., 1997; Gosselke et al., 2001; Plantegenest et al., 2001). Though these models are useful research tools they are generally unsuitable for decision making because they require too 
much data. However, to derive a correct management decision, forecasting tools cannot simply ignore these various sources of uncertainty. Beside the uncertainty resulting from the intrinsic variability of the system, a second source of uncertainty arises from sampling distribution of the parameter values (Ellner and Fieberg, 2003).

Bayesian probability theory provides an accurate general framework for the elaboration of decision-making systems under uncertainty (Berger, 1985; Ellison, 1996). By considering parameters as random variables, Bayesian inference provides an explicit expression of the amount of uncertainty in parameter estimates (Ellison, 1996). Let $y=\left\{z_{j}, x_{j}\right\}$ be an observed data set where $\left\{z_{j}\right\}$ is a set of vector of response variables, and $\left\{x_{j}\right\}$ a set of vector of explicative variables. Let $f$ be a structural relationship linking $x$ to $z, z=f(x)$, where $f$ is characterised by a vector of parameters $\beta$. The specificity of the Bayesian approach is to consider $\beta$ as a random variable of which an a priori distribution is assumed. Let $\beta_{i}$ denote one particular value of the vector $\beta$ (a particular state of nature). Given a data set $y$, a joint posterior conditional distribution of any vector of values of the model parameters $p\left(\beta_{i} \mid y\right)$ can be calculated using Bayes' theorem:

$$
p\left(\beta_{i} \mid y\right)=\frac{p\left(\beta_{i}\right) \cdot L\left(y \mid \beta_{i}\right)}{p(y)}
$$

where $p\left(\beta_{i}\right)$ is the prior distribution of $\beta$

$L\left(y \mid \beta_{i}\right)$ is the likelihood of the data conditionally to $\beta_{i}$

$p(y)$, is the probability of observing the data set (used to normalise the posterior density) (Gelman et al., 1995).

Through Bayes' theorem our prior knowledge is weighted by the likelihood function to provide posterior expectations (Box and Tiao, 1992). $p\left(\beta_{i} \mid y\right)$ can be interpreted as a measure of credibility of $\beta_{i}$ if its prior probability and the observed data set are given.

In the context of prediction, after the joint posterior probability had been evaluated on the available data sets, for any value of $x$, a random sample can be drawn from the posterior probability distribution of $\beta$ to generate the expected distribution of the variable of interest $z$. Bayesian approach applied to ecological decision making is promising and many applications have been proposed (Clark, 2003a; Ellison, 2004; Rivot et al., 2004). However, few have been developed for pest management (Parisetti, 1983; Gold et al., 1990; Tari, 1996). The purpose of this paper is to exemplify this powerful approach through its application to the design of a user-friendly model based on a temperature dependent simulation of $R$. padi population dynamics during autumn in cereal fields to assess the risk of BYD epidemics.

\section{Materials and Methods}

\subsection{Data set.}




\subsubsection{Aphid sampling.}

The data set contained 52 records of field monitoring carried out from 1989 to 1999 in 18 locations in the most important French small grain production areas of the northern half of France. Experimental fields were sown in early autumn (mid September to mid October) with winter barley susceptible varieties (cvs Alaska, Esterelle, Intro, Keliba, Gaelic, Labéa, Rossini). Observations were carried out in four replicates receiving no insecticide sprays. Plot size was $3 \times 11 \mathrm{~m}$. Plots were allowed to be spontaneously colonised by aphids. R. padi populations were monitored at 5 to 14 day intervals from crop emergence to about the end of November. Counts were done in each plot in 4 randomly chosen locations. In each location, 25 consecutive plants were examined along the same row. From 1989 to 1994, the number of wingless and the number of winged aphids were recorded on each plant, as well as the proportion of plants infested by at least one aphid and the proportion of plants infested by winged aphids alone. From 1995 to 1999, the proportion of plants infested by at least one aphid and the proportion of plants infested by winged aphids alone were recorded. Growth stage of the barley was also recorded at each sampling occasion using the decimal code proposed by Zadoks et al. (1974). The first data set (1989-94), 27 field experiments including 180 sampling dates - data set 1) was used for parameter estimation of the model and the second one (1995-99), 25 field experiments - data set 2) was used for model validation. Both data set represents a wide range of agricultural, climatic and aphid infestation conditions.

\subsubsection{Temperature.}

The daily maximum and minimum temperatures were collected from the Météo France ${ }^{\circledR}$ network stations in standardised conditions ( $2 \mathrm{~m}$ high under a shelter). Stations were chosen as close as possible to the experimental locations (at a maximum of 50 kilometres apart).

\subsection{BYD risk assessment model.}

\subsubsection{General scheme of the system}

Four steps are involved in the BYD risk assessment model.

Step 1: A field assessment of the proportion of plants at growth stages DC 11 or DC 12 infested by aphids is carried out. This observation is used to derive $F(0)$, the probability distribution of the actual proportion of plants infested by aphids at time $t=0$, as explained in the section 2.2.2.

Step 2: A sample of $N b_{\text {sim }}$ values, $\left\{F_{i}(0)\right\}_{1 \leq i \leq N b s i m}$, is drawn from the distribution $F(0)$ and used to generate a sample of $N b_{\text {sim }}$ values of the initial average number of aphids per 100 plants, $\left\{N_{i}(0)\right\}_{1 \leq i \leq N b s i m}$, as explained in the section 2.2.3. 
Step 3: Observed daily minimum and maximum temperatures at date $t\left(\theta \min _{t}\right.$ and $\left.\theta \max _{t}\right)$ are used to generate $r(t)$, the probability distribution of the population growth rate. For each initial average number of aphids and for each date $t<\operatorname{tmax}$ (tmax being fixed at the end of November), a value $r_{i}(t)$ is drawn from $r(t)$ and used to calculate $N_{i}(t+1)$ from $N_{i}(t)$, as explained in the section 2.2.4.

Step 4: The $N b_{\text {sim }}$ simulated population dynamics, $\left\{N_{i}(t)\right\}_{(1 \leq i \leq N b s i m, 0 \leq t \leq t \max )}$, are used to generate a sample $\left\{I_{i}\right\}_{1 \leq i \leq N b s i m}$ (as explained in the section 2.3). The sample $\left\{I_{i}\right\}_{1 \leq i \leq N b s i m}$ provides a posterior predictive distribution of the risk index $I$.

$N b_{\text {sim }}$ was fixed to $6.10^{5}$. The program was implemented in Turbo Pascal with Borland Delphi $6.0^{\circledR}$.

\subsubsection{Assessment of the probability distribution $F(0)$.}

A field assessment of the proportion $f$ of plants infested by $R$. padi at the cereal growth stages one leaf or two leaves (DC 11 or 12) is carried out by observing $n$ contiguous plants in $N_{Q}$ quadrats. $F(0)$ the probability distribution of the actual proportion of plants infested by aphids at time $t=0$ is assumed to follow a normal distribution with mean $f$ and variance $f \cdot(1-f) / n N_{Q}$ (Madden and Hughes, 1999). A presence/absence notation was preferred to a precise counting of the number of aphids to simplify sampling procedure.

\subsubsection{Conditional probability distribution $\mathrm{P}[N \mid F]$.}

Data set 1 was used to produce a sample (denoted thereafter $\{P, N\}$ ) of 180 observed couples $\left(F_{i}, N_{i}\right)$ to investigate the relationship between the proportion of infested plants and the average number of aphids per 100 plants. $N$ was assumed to follow a log-normal distribution with mean $\mu_{N}=a \cdot[\exp (b \cdot F)-1]$ and variance $\sigma_{N}^{2}$. Accordingly, the following model was fitted to data set 1 (Fig. 1) :

$$
N_{i}=a \cdot\left[\exp \left(b \cdot F_{i}\right)-1\right] \cdot \exp \left(\omega_{i}\right) \quad \text { equation (1) }
$$

where $a$ and $b$ are real coefficients and $\omega_{i}$ are independent random variables normally distributed with mean 0 and variance $\sigma_{N}^{2}$.

The term $\exp \left(\omega_{i}\right)$ is a multiplicative log-normal process error.

Following Gelman et al. (1995), as many experimental data were available and few parameters had to be estimated, non-informative prior distributions were considered $([a, b] \sim$ Uniform on $\left.\left.\left.] 0,10^{4}\right] \times\right] 0,10^{4}\right]$ and $\sigma_{N}^{2} \sim$ Gamma inverse $\left.\left[10^{-3}, 10^{-3}\right]\right)$. A sample of 5000 draws of the joint posterior probability distribution $P\left(a, b, \sigma_{N}^{2} \mid\{P, N\}\right)$ was generated using Markow Chain Monte Carlo (MCMC) techniques (Gibbs sampling algorithm [Gelman et al., 1995]) with Winbugs ${ }^{\circledR}$ V1.3 (Spiegelhater et al., 2000) after convergence of the chains had been checked with the Brooks and Gelman (1998) diagnostic proposed by Winbugs ${ }^{\circledR}$. 
The marginal posterior distributions of the three parameters were directly computed from the MCMC samples (Fig. 2A).

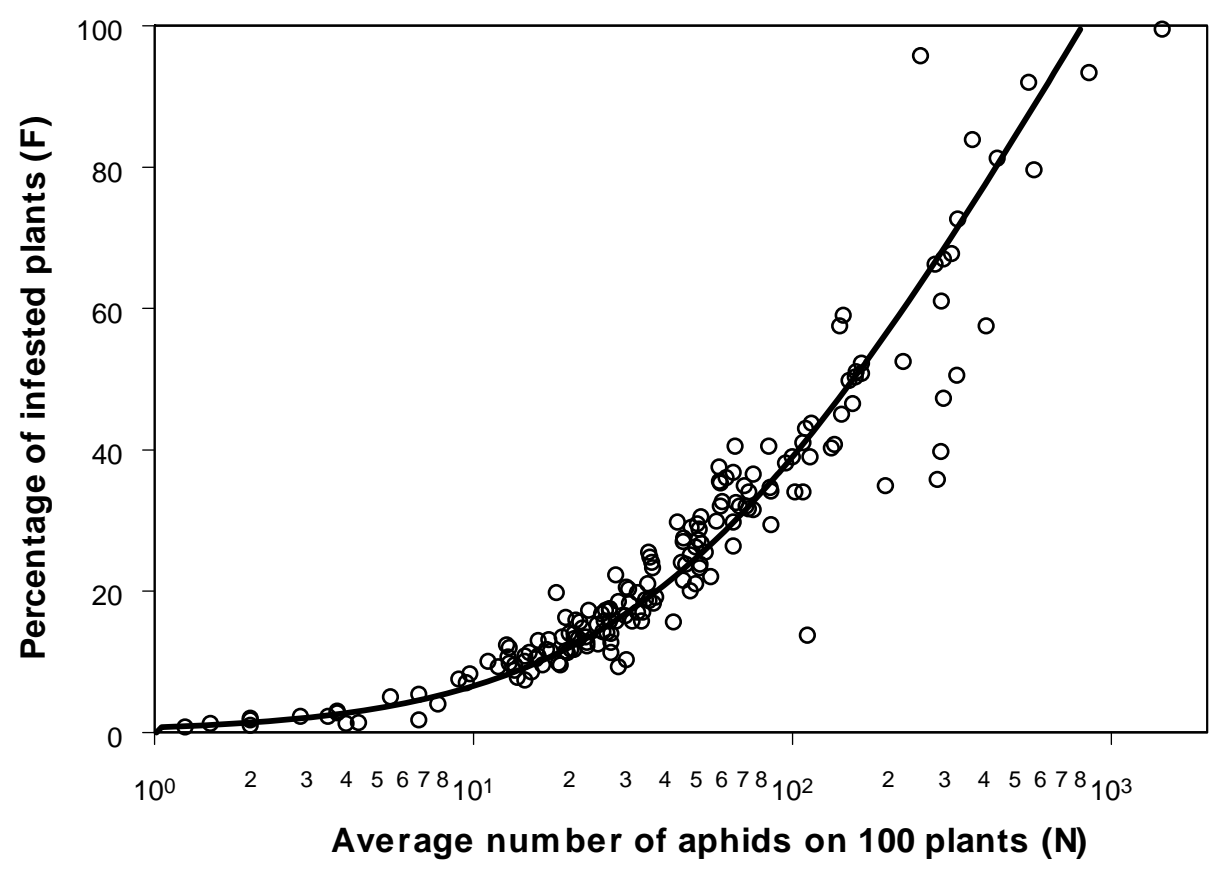

Fig. 1. Proportion of plants infested by Rhopalosiphum padi, F, as a function of the average number of aphids per 100 plants, $N$ (observation: open circles; model: line).

\subsubsection{Modelling the population dynamics of $R$. padi.}

Population dynamics of $R$. padi were described by a density-independent exponential model with a variable growth rate:

$$
N_{t+\Delta t}=N_{t} \cdot \exp [r(t) \cdot \Delta t] . \quad \text { equation (2) }
$$

where $N_{t}$ is the average number of aphids per 100 plants on day $t$ and $r(t)$ the population growth rate between $t$ and $t+\Delta t$.

Population growth rate. Growth rate was assumed to be temperature-dependent and to follow a linear day-degree model. A set of observed values of $r$ was obtained by using equation 2 for each pair of consecutive sampling densities $\left(N_{t}, N_{t+\Delta t}\right)$ from the data set 1 . During the 2 consecutive dates, the mean daily rate of degree-day accumulation was computed as 


$$
D D=\frac{1}{\Delta t} \cdot \sum_{k=1}^{\Delta t}\left(\frac{\theta \min _{k}+\theta \max _{k}}{2}-5.8\right) \quad \text { equation (3) }
$$

where $\theta \min _{k}$ and $\theta \max _{k}$ are the minimum and maximum temperatures recorded on the day $k$ and $5.8^{\circ} \mathrm{C}$ is the lower developmental threshold for R. padi (Elliott and Kieckhefer, 1989).

A
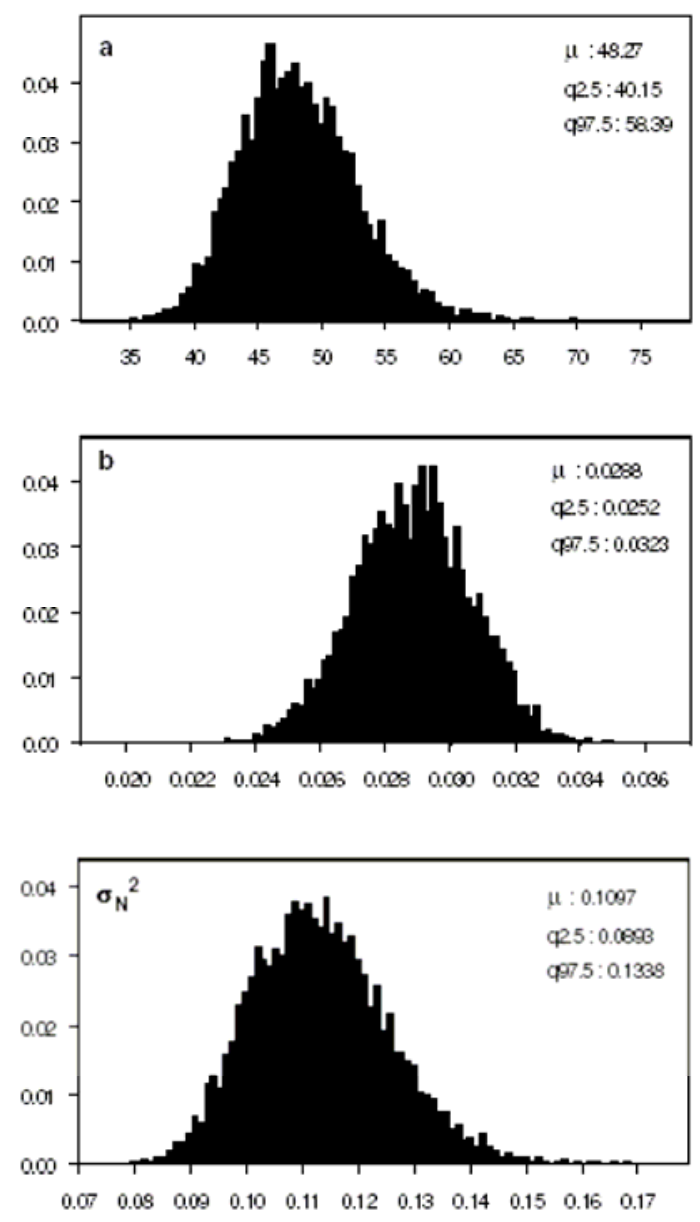

B
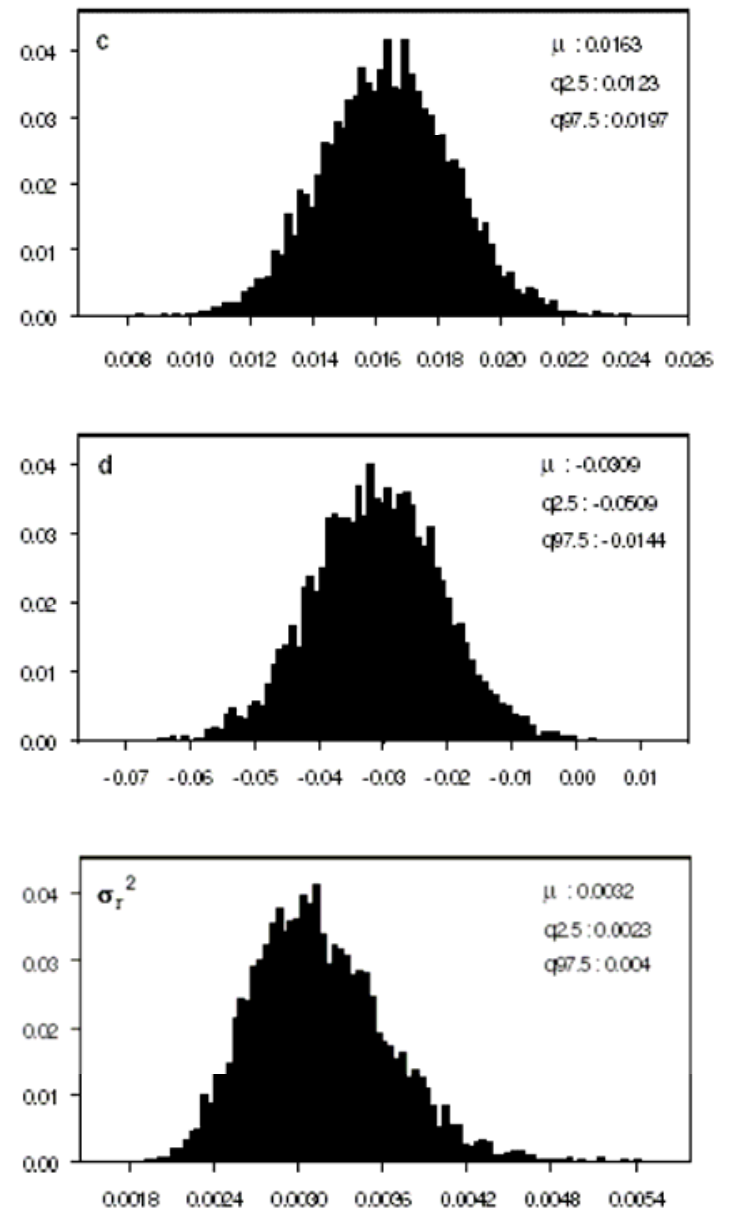

Fig. 2. A: Posterior marginal probability distribution of equation 1 parameters $\left(a, b, \sigma_{N}^{2}\right)$. B: Posterior marginal probability distribution of equation 4 parameters $\left(c, d, \sigma_{r}^{2}\right)$. The mean $(\mu)$, $2.5 \%$ (q2.5) and $97.5 \%$ (q97.5) quantiles of the posterior marginal probability distribution are computed from a MCMC sample of 5000 draws.

As in the northern part of France temperatures above $25^{\circ} \mathrm{C}$ are extremely uncommon after September $15^{\text {th }}$, no specific control of the effect of high temperatures has been implemented. For the sake of simplicity, stochasticity due to sampling has not been taken into account and counts with less than 100 aphids in the 4 plots were not considered in order to avoid the 
effects of random fluctuations attributable to small sample size. Some observations presenting a drastic decrease of the aphid population just after insecticide applications in an adjacent plot were also removed from the data set. The linear day-degree model was fitted to the data set containing the 99 remaining observed pairs $\left\{\left(r_{i}, D D_{i}\right)\right\}$ (Fig. 3):

$$
r_{i}=c \cdot D D_{i}+d+\eta_{i} \quad \text { equation (4) }
$$

where $c$ and $d$ are real coefficients and $\eta_{i}$ are independent random variables normally distributed with mean 0 and variance $\sigma_{r}^{2}$.

A sample of 5000 draws of the joint posterior probability distribution of the 3 parameters was generated with Winbugs ${ }^{\circledR}$ using non informative prior distribution $\left([c, d] \sim\right.$ Uniform on $\left[-10^{4}\right.$, $\left.10^{4}\right] \times\left[-10^{4}, 10^{4}\right]$ and $\sigma_{r}^{2} \sim$ Gamma inverse $\left.\left[10^{-3}, 10^{-3}\right]\right)$. The marginal posterior distributions of the 3 parameters are presented in Fig. $2 \mathrm{~B}$.

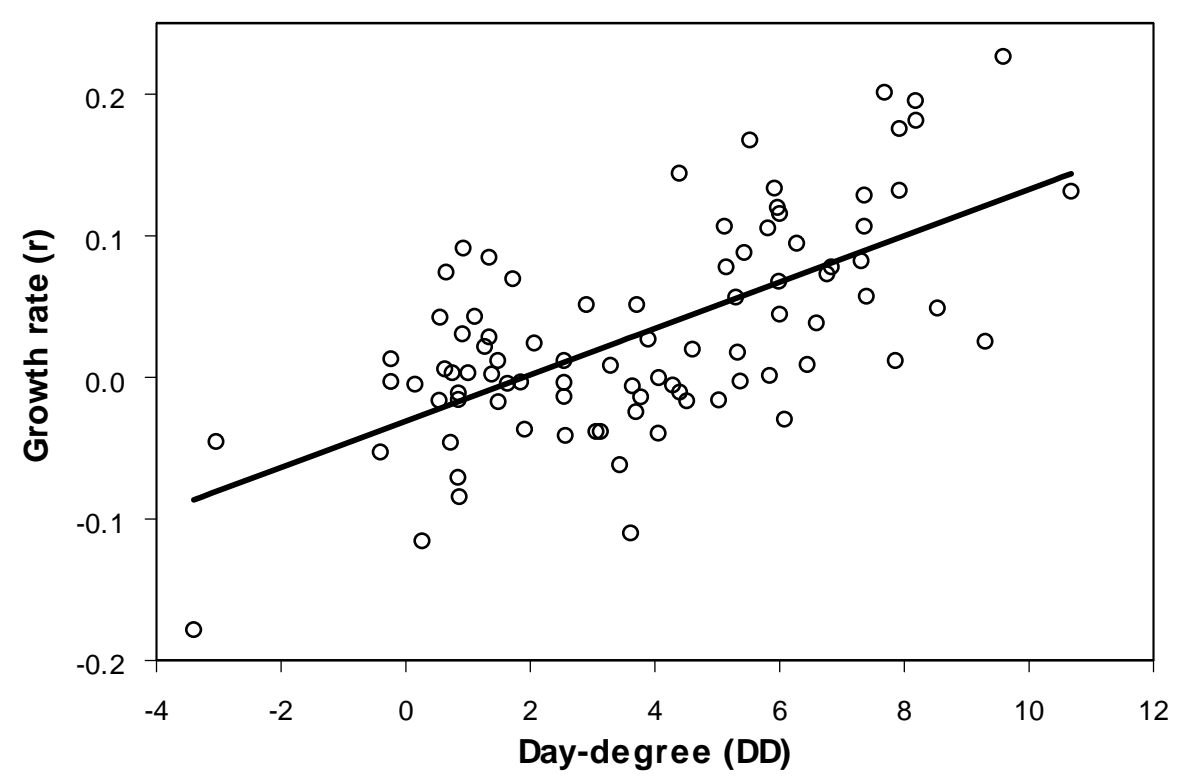

Fig. 3. Growth rate of $R$. padi populations $(r)$ in cereal field conditions in autumn as a function of the mean daily rate of day-degree accumulation over a $5.8^{\circ} \mathrm{C}$ threshold $(D D)\left(\mathrm{r}^{2}=0.42, \mathrm{n}=99\right.$, $\mathrm{p}<10-3)$.

Growth rate estimation under low temperature regime. Because of the scarcity of observations in which the recorded temperature was below $0^{\circ} \mathrm{C}$ in the data set, the method used above was irrelevant for growth rate assessment at low temperatures. Below $-5^{\circ} \mathrm{C}$, many authors (Griffiths and Wratten, 1979; Williams, 1980; Dedryver and Gellé, 1982) have stated that high rates of mortality occurred in $R$. padi populations. Few $R$. padi survive under $-8^{\circ} \mathrm{C}$. From these qualitative observations, below $-5^{\circ} \mathrm{C}$ the population growth rate was set to:

$$
r=h-\frac{1}{\theta_{\min }+e} \quad \text { equation (5) }
$$


where $\theta$ min is the minimum temperature of the considered day and $e$ and $h$ are real coefficients set to 8.41 and 0.125 respectively to achieve a daily mortality rate of $15 \%$ of the population at $-5^{\circ} \mathrm{C}$ and of $90 \%$ at $-8^{\circ} \mathrm{C}$.

\subsection{Validation of the BYD risk assessment model.}

The validation was performed by checking whether the population dynamics model accurately predicts the value of the BYD risk index $I$ for the 25 independent field records (data set 2). To estimate $I$, the area under the curve describing aphid population dynamics, the trapezoidal integration method was used. To avoid the influence of the length of the time interval of the survey on the value of $I$, it was rescaled by dividing it by its duration. $I$ was calculated with both the actual observed dynamics of aphid (Iob) and predicted dynamics produced by the model (Ipr) after simulated aphids densities [i.e. $\left\{N_{i}(t)\right\}_{(1 \leq i \leq N b s i m, 0 \leq t \leq t m a x)}$ ] were expressed in proportions of infested plants using the reciprocal of equation 1 with mean values of $a$ and $b$. For each monitored field, 2 simulations were run: one with actual observed temperatures and one with 20 year average temperatures. For $I o b$, the four replicates enabled the production of a $90 \%$ confidence interval under the assumption of a normal distribution. For $\mathrm{Ipr}$, the $50 \%$ and $90 \%$ posterior intervals were derived from their posterior predictive distribution with $5 \%, 25 \%, 75 \%$ and $95 \%$ quantiles.

\section{Results}

\subsection{Validation using actual temperatures.}

The regression analysis ( $I p r=0.81 I o b, \mathrm{n}=25, \mathrm{r}^{2}=0.89, \mathrm{P}<0.0001$ ) indicated that the simulation model run with actual temperatures accurately predicted $I o b$ (Fig. 4). However, the model tended to slightly underestimate the actual value of $I$ as the regression slope was 0.81 . In 21 field experiments out of 25 (84\%) the 90\% confidence interval of $I o b$ and $90 \%$ posterior interval of $\mathrm{Ipr}$ overlapped. 


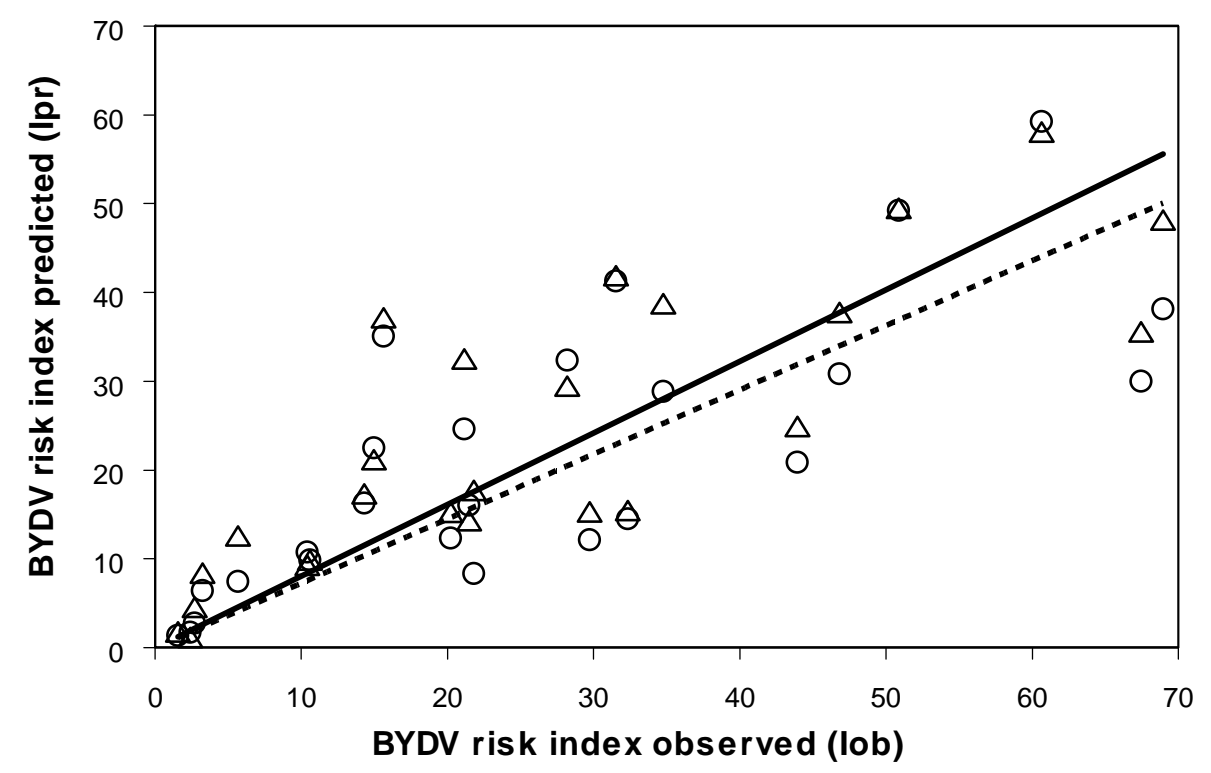

Fig. 4. Relationship between mean observed value of the BYDV risk index $(I o b)$ and its mean predicted value $(I p r)$ for simulations ran with actual observed temperatures $(\triangle$, Solid line $: \mathrm{n}=25$, $\left.\mathrm{r}^{2}=0.89, \mathrm{P}<0.0001\right)$ and with 20 year average temperatures $\left(\mathrm{O}\right.$, Dotted line : $\mathrm{n}=25, \mathrm{r}^{2}=0.85$, $\mathrm{P}<0.0001)$.

\subsection{Validation with 20 year average temperatures.}

Similar results were obtained when 20 year average daily temperatures were used (Ipr $=0.74$ Iob $\left., n=25, \mathrm{r}^{2}=0.85, \mathrm{P}<0.001\right)$ (Fig. 4). The underestimation of the actual value of $I o b$ was slightly higher than for actual temperatures. However, the slopes of the regression lines obtained with 20 year average temperatures (0.74) and with actual observed temperatures (0.81) were not significantly different (student's t-test $=0.46, \mathrm{df}=46)$. In 21 field experiments out of $25(84 \%)$ the $90 \%$ confidence interval of $I o b$ and $90 \%$ posterior interval of Ipr overlapped (Fig. 5). In the 4 other field experiments, Ipr values were always underestimated. In these 4 experiments, the mean value of the area under the curve of the percentage of plants infested by winged aphids after $t=0$ is 48.2 ( $\mathrm{SD} \pm 39.6$ ) versus only 26 $(\mathrm{SD} \pm 28.5)$ in the 21 fields experiments where confidence intervals overlapped, suggesting that this discrepancy could be attributed to substantial infestations of the field after the date of initialisation of the simulation. 


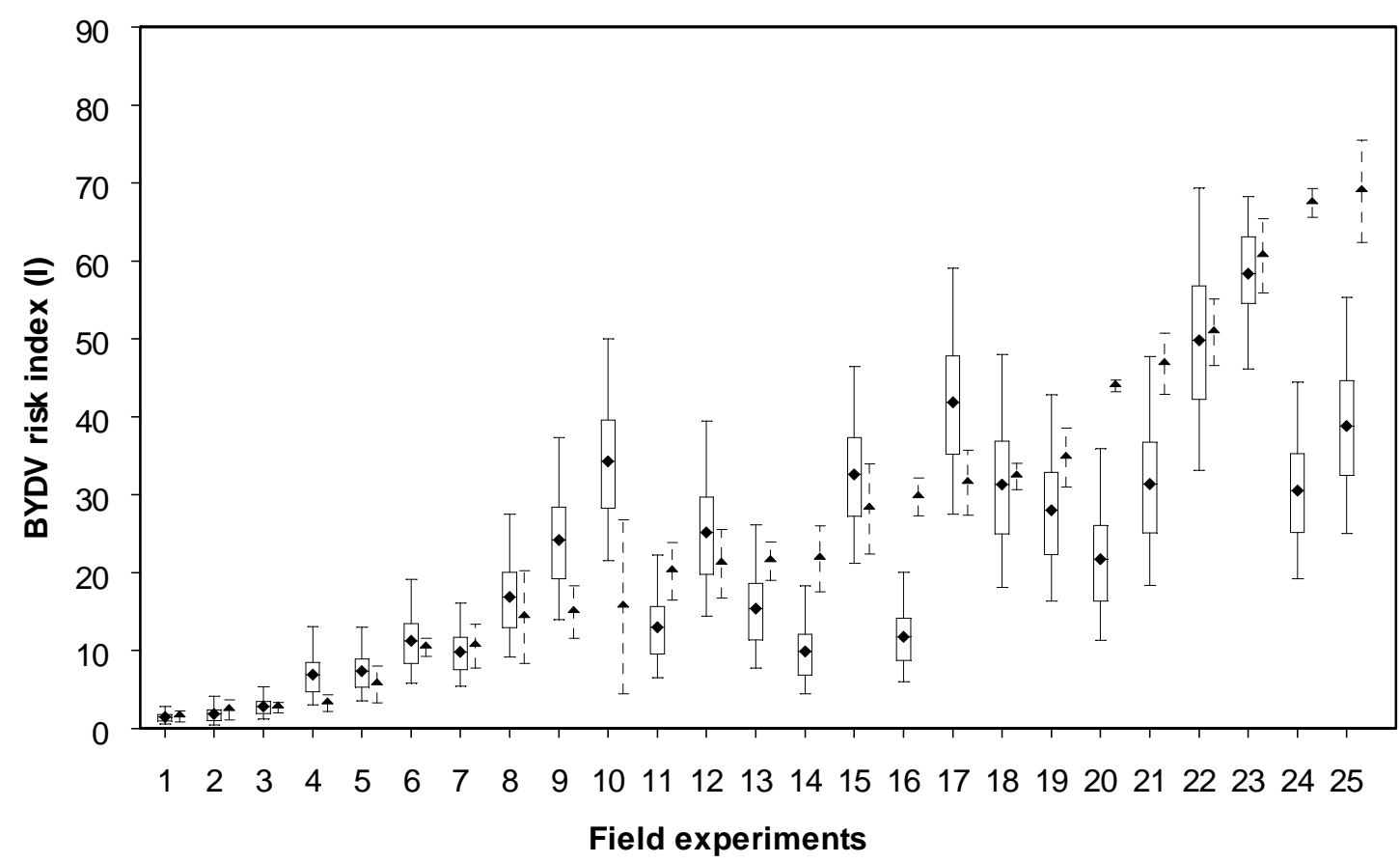

Fig. 5. Mean ( $\boldsymbol{\Delta}$ ) and 90\% confidence interval (broken lines) of Iob and box plot of Ipr predicted with 20 year average temperatures for the 25 field experiments. The boxes indicate the first and upper quantiles and the diamonds ( $\bullet$ ) indicate the mean of Ipr. Full lines extending from each end of the box show the extent of the $90 \%$ posterior intervals (derived from the posterior predictive distributions with the 5 and $95 \%$ quantiles). For $I o b$, a $90 \%$ confidence interval was estimated assuming a normal distribution (mean $\pm 1.65 \mathrm{SD}$ ).

\section{Discussion}

In spite of its simplicity, the population dynamics model provided accurate estimates of the BYD risk index proposed by Fabre et al. (2003). The model is initialised with a single estimate of the proportion of plants infested by aphids when others often needs as starting values fields densities of aphids and of their natural enemies (e.g. Gosselke et al., 2001; Plantegenest et al., 2001). In R. padi, as in many aggregative insects (Wilson and Room, 1983), population density is strongly linked to the proportion of infested plants allowing us to accurately estimate the average number of aphids per plant from an observation of this proportion. This is a pledge of good use by decision-makers because, unlike counting aphid and natural enemies numbers, this proportion is relatively easy to assess in fields. However this sampling needs to be done thoroughly to avoid mis-counting and decision-makers may undoubtedly require some basic training and instructions on making such observations. A further easier alternative could be to use suction trap data to estimate the daily immigration 
rate of $R$. padi into the field (Morgan, 2000). However, in France, suction traps are very distant from each others and the network only covers the northern part of the country, which limit their practical use. Moreover, many factors can affect aphids settling in crops such as topography or locally dominant reproductive mode of $R$. padi (Simon et al., 1996; Rispe et al., 1998). Skirvin et al. (1997) emphasized that suction traps catches cannot account for differences in the simultaneous dynamics of Sitobion avenae in two neighbouring fields. In this context, field sampling achieves the best trade-off between reliability and easiness for an accurate assessment of initial aphid density.

The BYD risk assessment was based on simulation of the population dynamics of the main BYDV vector in autumn-sown cereals, the aphid $R$. padi. Few population dynamics models have been proposed for R. padi (Wiktelius and Pettersson, 1985; Gosselke et al., 2001) and the model of Morgan (2000) was the only one to deal with its autumnal dynamics. Models describing aphid population dynamics are usually deterministic (Carter et al., 1982; Wiktelius and Pettersson, 1985; Skirvin et al., 1997; Ro and Long, 1999; Morgan, 2000; Gosselke et al., 2001; Plantegenest et al., 2001) and, except in Ro and Long (1999), parameter estimation relies on laboratory experiments. The innovative approach described here used stochastic modelling and dealt with field data. Indeed, to our view, the complex array of environmental variables and feedback loops driving aphid abundance in natural conditions can, in some cases, limit the reliability of parameters estimated under controlled conditions. The noisy character of field data compelled us to use a simple model including few parameters. A density-independent exponential model with a variable growth rate depending only on temperature was chosen because this variable is known to have the strongest influence on aphid dynamics in a temperate climate (Dean, 1974; Griffiths and Wratten, 1979; Williams, 1980; Elliott and Kieckhefer, 1989). The effect of temperature was introduced, as in Ro and Long (1999), through a mean-minus base degree day method. The density-independent assumption was justified by the fact that $R$. padi rarely achieved high densities during the period studied (in our data set, the average density per infested plant was $2.32 \pm 2.26$ ). Thirakhupt and Araya (1992) have shown that no decrease of the $R$. padi population growth rate is observed for densities below 5 to 10 aphids per plant.

Despite the major effect of temperature on $R$. padi population dynamics, the moderate coefficient of determination of equation 3 (0.42) suggests that many other factors drive the abundance of aphid populations in field conditions. Bayesian inference is well adapted to deal with such large sources of uncertainty. It allows explicit incorporation into the model of the uncertainty attributable to sampling errors and to uncontrolled factors which drive the pattern of $R$. padi aggregation on plants and the population growth rate in the field. Rather than a single mean estimation of aphid densities, as derived by previously listed deterministic models, the whole posterior probability density function of aphid densities is obtained. The 
model validation carried out on a large independent data set collected under normal farm working conditions showed that this modelling strategy was efficient.

The main limitation to the use of climate driven systems is that future climate cannot be accurately predicted. However, comparison of the results obtained by simulations with actual daily observed temperatures and 20 year average daily temperatures has shown only a weak reduction in accuracy of the model's predictions. Moreover, simulations were run successfully with early field sampling (GS 11 or 12) when insecticide spray against BYD can still be applied. Consequently, the model was shown to be suitable in an actual predictive context where only past climate and early population density estimates are available. To further improve its interest, the model should be fit to wheat, BYD being also a major problem on this crop. To our view, the main adjustment should come from difference in the relationship between growth rate and temperatures. Indeed, authors generally reports that, at early growth stages (i.e. in autumn), R. padi has lower fecundity on wheat than on barley (Leather and Dixon, 1981 ; Kieckhefer and Gellner, 1988).

In many cases the model underestimated weakly the actual value of $I$. Differences in barley varieties for $R$. padi settling and multiplication are generally low (Forslund et al., 1998) and do not seem to play a role in this discrepancy. This could be due to later colonisation events occurring after $t=0$. The large degree of year to year variation in the number of migrating individuals as well as in the length of the colonisation period, render migration process difficult to model (Gosselke et al., 2001). However, model discrepancy remained relatively moderate for two main reasons: the effect of colonisation on field population dynamics becomes smaller when the number of wingless aphids increases, and the number of flying $R$. padi decreases rapidly in the second half of October (Hullé et al., 1994). In practice, to deal with the risk of late colonisation, users could continue monitoring their fields until mid-October. This choice was made by Gosselke et al. (2001) to adapt the simulated immigration to the true occurrence of immigrants. An alternative approach could be to introduce a stochastic variable accounting for the colonisation process occurring after $t=0$ in the model but this would result in an enlargement of the predicted confidence interval. However, one must bear in mind that this problem can be get around when using the value of $I$ to derive a binary response on whether or not applying a treatment. Indeed, to do so, the value of $I$ predicted in a given field is compared with a decision threshold value (Is), a particular value of $I$, determined using cost-benefit analysis (Fabre et al., 2003). Accordingly, it is not a strict requirement that $I$ quantifying the exact value of the area under the proportion of plants infested by $R$. padi because the decision rely on the comparison between relative values of $I$. Within such decision making framework, a deterministic model will provide a point estimate of $I$ : only a binary response can be derived (i.e. $I>I s$ or $I \leq I s$ ). In the opposite, the Bayesian approach is more informative: based on the posterior probability density 
function of $I$, an estimation of the probability that a treatment is necessary (i.e. the probability that $I>I s$ ) can be obtained.

Bayesian inference is fast becoming an accepted statistical tool among ecologists (Ellison, 2004) and natural resource managers (e.g. Rivot et al., 2004; Prato, 2005). This work exemplified its advantages and high tractability in integrated pest management. Besides its practical efficiency evidenced in this work, the Bayesian methodology allows us to associate any prediction with a measure of its reliability that is generally not the case when dealing with deterministic models. As emphasised by Clark (2003b), ignoring uncertainty in model parameters lead to narrows confidence intervals, to forecast failure and finally to a loss of credibility in decision making systems.

\section{Acknowledgments}

The authors are grateful to J. L. Leterrier (Bayer Crop Science) for providing data. F. Fabre was supported by the C.I.F.R.E. grant from the Association Nationale de la Recherche Technique and Bayer Crop Science. They also like to thank two anonymous reviewers for theirs helpful comments.

\section{References}

Araya, J. E. and Foster, J. E., 1987. Laboratory study on the effects of barley yellow dwarf virus on the life cycle of Rhopalosiphum padi (L.). J. Plant Dis. Prot., 94: 578-583.

Araya, J. E. and Fereres, A., 1991. Cereal aphid survival under flooding conditions. J. Plant Dis. Prot., 98: 168-173.

Berger, J. O., 1985. Statistical decision theory and Bayesian analysis $\left(2^{\text {nd }}\right.$ Ed). Springer-Verlag, New York, NY, 617 pp.

Box, G. E. P. and Tiao, G. C., 1992. Bayesian inference in statistical analysis. John Wiley and Sons, New York and London, 588 pp. 
Brooks, S. P. and Gelman, A., 1998. Alternative methods for monitoring convergence of iterative simulations. J. Comput. Graph. Stat., 7: 434-455.

Campbell, A., Frazer, B. D., Gilbert, N., Gutierrez, A. P. and Mackauer M., 1974. Temperature requirements of some aphids and their parasites. J. Appl. Ecol., 11: 431-438.

Carrigan, L. L., Ohm, H. W., Foster, J. E. and Patterson, F. L., 1981. Response of winter wheat cultivars to barley yellow dwarf virus infection. Crop Sci., 21: 377-380.

Carter, N., Dixon, A. F. G. and Rabbinge, R., 1982. Cereal aphid populations: biology, simulation and prediction. Center for Agricultural Publishing, Wageningen, 91 pp.

Cisar, G., Brown, C. M. and Jedlinski, H., 1982. Effect of fall or spring infection and sources of tolerance of barley yellow dwarf of winter wheat. Crop Sci., 22: 474-478.

Clark, J. S., 2003a. Uncertainty in ecological inference and forecasting. Ecology, 84: 1349-1350.

Clark, J. S., 2003b. Uncertainty and variability in demography and population growth: a hierarchical approach. Ecology, 84: 1370-1381.

Dean, G. J. W., 1973. Bionomics of aphids reared on cereals and some Gramineae. Ann. Appl. Biol., 73: 127-135.

Dean, G. J. W., 1974. Effect of temperature on the cereal aphids Metopolophium dirhodum (Wlk.), Rhopalosiphum padi (L.) and Macrosiphum avenae (F.) (Hem., Aphididae). B. Entomol. Res., 63: 401-409.

Dedryver, C. A. and Gellé, A., 1982. Etude de l'hivernation de populations anholocycliques de Rhopalosiphum padi (L.), Metopolophium dirhodum (Wlk.) et Sitobion avenae (F.) sur repousses de céréales, dans trois stations de Bretagne et du Bassin parisien. Acta oecologica Oecol. Applic., 3: 321 342.

Elliott, N. C. and Kieckhefer, R. W., 1989. Effects of constant and fluctuating temperatures on immature development and age-specific life tables of Rhopalosiphum padi (L.) (Homoptera: Aphididae). Can. Entomol., 121: 131-140.

Ellison, A. M., 1996. An introduction to Bayesian inference for ecological research and environmental decision-making. Ecol. Appl., 6: 1036-1046. 
Ellison, A. M., 2004. Bayesian inference in ecology. Ecol. Lett., 7:509-520.

Ellner, S. P. and Fieberg, J., 2003. Using PVA for management despite uncertainty: effects of habitat, hatcheries, and harvest on salmon. Ecology, 84: 1359-1369.

Fabre, F., Dedryver, C. A., Leterrier, J. L. and Plantegenest, M., 2003. Aphid abundance on cereals in autumn predicts yield losses caused by BYDV. Phytopathology, 93: 1217-1222.

Forslund, K., Pettersson, J, Ahmed, E. and Jonsson, L., 1998. Settling behaviour of Rhopalosiphum padi (L.) in relation to cyanogenetic glycosides and gramine contents in barley. Acta Agric. Scand. B, 48 (2) 107-112.

Gelman, A., Carlin, J., Stern, H. and Rubin, D., 1995. Bayesian data analysis. Chapman and Hall, London and New York, 526 pp.

Gillet, H., Dedryver, C. A., Robert, Y., Gamon, A. and Pierre, J. S., 1990. Assessing the risk of primary infection of cereals by BYDV in autumn in the Rennes basin of France. Ann. Appl. Biol., 117: 237-251.

Gold, H. J., Wilkerson, G. G., Yu, Y. N. and Stinner, R. E., 1990. Decision analysis as a tool for integrating simulation with expert systems when risk and uncertainty are important. Comput. Electron. Agr., 4: 343-360.

Gosselke, U., Triltsch, H., Rossberg, D. and Freier, B., 2001. GETLAUS01 - the latest version of a model for simulating aphid population dynamics in dependence on antagonists in wheat. Ecol. Mod., 145: 143-157.

Griffiths, E. and Wratten, S. D., 1979. Intra- and inter-specific differences in cereal aphid lowtemperature tolerance. Entomol. Exp. Appl., 26: 161-167.

Irwin, M. E. and Thresh, J. M., 1990. Epidemiology of barley yellow dwarf: a study in ecological complexity. Ann. Rev. Phytopathol., 28: 393-424.

Hullé, M., Coquio, S. and Laperche, V., 1994. Patterns in flight phenology of a migrant cereal aphid species. J. Appl. Ecol., 31: 49-58. 
Kendall, D. A., Brain, P. and Chinn, N. E., 1992. A simulation model of the epidemiology of barley yellow dwarf virus in winter sown cereals and its application to forecasting. J. Appl. Ecol., 29: 414426.

Kieckhefer, R. W. and Gellner, J. L., 1988. Influence of plant growth stage on cereal aphid reproduction. Crop Sci., 28: 688-690.

Leather, S. R. and Dixon, A. F. G., 1981. The effect of cereal growth stage and feeding site on the reproductive activity of the bird cherry-oat aphid, Rhopalosiphum padi. Ann. Appl. Biol., 97: 135-141.

Leclercq-Le Quillec, F., Plantegenest, M., Riault, G. and Dedryver, C. A., 2000. Analyzing and modeling temporal disease progress of barley yellow dwarf virus serotypes in barley fields. Phytophatology, 90: 860-866.

Lister, R. M. and Ranieri, R., 1995. Distribution and economic importance of barley yellow dwarf. In: C. J. D'Arcy and P. A. Burnett (Editors), Barley yellow dwarf: 40 years of progress, American Phytopathological Society, St Paul, pp. 29-54.

Madden, L. V. and Hughes, G., 1999. Sampling for plant disease incidence. Phytopathology, 89: 10881103.

Morgan, D., 2000. Population dynamics of the bird cherry-oat aphid, Rhopalosiphum padi (L.), during the autumn and winter: a modelling approach. Agr. Forest Entomol., 2: 297-304.

Parisetti, C. C., 1983. A Bayesian approach in the estimation of the abundance of an insect population. In: R. Cavalloro (Editor), Statistical and Mathematical Methods in Population Dynamics and Pest Control, Proc. of a Meeting of the EC' experts' group, Parma, Italie, 26-28 October 1983, pp. 58-61.

Plantegenest M., Pierre J. S., Dedryver C. A. and Kindlmann, P., 2001. Assessment of relative impact of different natural enemies species on population dynamics of the grain aphid, Sitobion avenae (Homoptera: Aphididae) in the field. Ecol. Entomol., 26: 404-410.

Plumb, R. T., 1990. The epidemiology of barley yellow dwarf in Europe. In: P. A., Burnett (Editor), World Perspectives on Barley Yellow Dwarf, CIMMYT, Mexico, pp. 215-227.

Plumb, R. T. and Johnstone, G. R., 1995. Cultural, chemical and biological methods for the control of Barley Yellow Dwarf. In: C. J. D'Arcy and P. A. Burnett (Editors), Barley yellow dwarf: 40 years of progress, American Phytopathological Society, St Paul, pp. 321-343. 
Prato, T., 2005. Bayesian adaptive management of ecosystems. Ecol. Mod., 183: 147-156.

Rispe, C., Hullé, M., Gauthier, J. P., Pierre, J. S. and Harrington, R., 1998. Effect of climate on the proportion of males in the autumn flight of the aphid Rhopalosiphum padi L. (Hom., Aphididae). J. Appl. Ent., 122: 129-136.

Rivot, E., Prévost, E., Parent, E. and Baglinière, J. L., 2004. A Bayesian state-space modelling framework for fitting a salmon stage-structured population dynamic model tomultiple time series of field data. Ecol. Mod., 179:463-485.

Rochow, W. F., 1969. Biological properties of four isolates of barley yellow dwarf virus. Phytopathology, 59: 1580-1589

Roe, T. H. and Long, G. E., 1999. GPA-Phenodynamics, a simulation model for the population dynamics and phenology of green peach aphid in potato: formulation, validation, and analysis. Ecol. Mod., 119: 197-209.

Simon, J. C., Dedryver, C. A., Pierre, J. S., Tanguy, S. and Wegorek, P., 1991. The influence of clone and morph on the parameters of intrinsic rate of increase in the cereal aphids Sitobion avenae and Rhopalosiphum padi. Entomol. Exp. Appl., 58: 211-220.

Simon, J. C., Carrel E., Hebert P. D. N., Dedryver C. A., Bonhomme. J. C. and Le Gallic, J. F., 1996. Genetic diversity and mode of reproduction in French populations of the aphid Rhopalosiphum padi (L.). Heredity, 76: 305-313.

Skirvin, D. J., Perry, J. N. and Harrington, R., 1997. A model describing the population dynamics of Sitobion avenae and Coccinella septempunctata. Ecol. Mod, 96: 29-39.

Spiegelhater, D. J., Thomas, A. and Best, N., 2000. Winbugs. Version 1.3. User Manual. MRC and Imperial College of Science, Technology and Medicine (http://www.mrcbsu.cam.ac.uk/bugs/winbugs/contents.shtml).

Tari, F., 1996. A Bayesian network for predicting yield response of winter wheat to fungicide programmes. Comput. Electron. Agr., 15: 111-121. 
Thirakhupt, V. and Araya, J. E., 1992. Survival and life table statistics of Rhopalosiphum padi (L.) and Sitobion avenae (F.) (Hom., Aphididae) in single or mixed colonies in laboratory wheat cultures. J. Appl. Ent., 113: 368-375.

Watson, M. A. and Mulligan, T. E., 1960. Comparison of two barley yellow dwarf viruses in glasshouse and field experiment. Ann. Appl. Biol., 48: 559-574.

Williams, C. T., 1980. Low temperature mortality of cereal aphids. Bulletin OILB/SROP, 3: 63-66.

Wiktelius, S. and Pettersson, J., 1985. Simulation of Bird Cherry - Oat aphid population dynamics: A tool for developing strategies for breeding aphid-resistant plants. Agric. Ecosyst. Environ., 14: 159170 .

Wilding, N., 1970. The effect of temperature on the infectivity and incubation periods of the fungi Entomophthora aphidis and Entomophthora thaxteriana for the pea aphid Acyrthosiphum pisum Harris. Proc. $4^{\text {th }}$ Int. Colloq. Insect Pathol., College Park, Maryland, pp. 84-88.

Wilson, L. T. and Room, P. M., 1983. Clumping patterns of fruit and arthropods in cotton, with implications for binomial sampling. Environ. Entomol., 12: 50-54.

Zadoks, J. C., Chang, T. T. and Konzak, D. F., 1974. A decimal code for the growth stages of cereals. Weed Res., 14: 415-421. 